\title{
Design of Microstrip Low Pass Filters
}

\author{
${ }^{* 1}$ Reşat Tüzün ve ${ }^{2}$ Nursel Akçam \\ ${ }^{* 1}$ Aselsan Inc., Ankara 06370, Turkey \\ ${ }^{2}$ Faculty of Engineering, Department of Electrical Electronic Engineering Gazi University, Turkey
}

\begin{abstract}
:
Microstrip technology is used for simplicity and ease of fabrication. Therefore, microstrip filters have a significant role in many applications in recent years. They are commonly used in microwave circuits, satellite communications, radars, test equipments and so on. Because microstrip filters are compact, cheap and easy to produce, they are highly preferred for microwave applications. Microwave filter; microwave system is a two-ported element used to control the frequency response at a certain point by attenuating the frequencies in the stop band by transmitting in the frequency band. Typical frequency responses are low pass, high pass, band pass and band stop. Also approaches such as Butterworth, Chebyshev, and Elliptic are defining filter characteristics. In this paper, microstrip low pass filters (LPF) having Chebyshev, Elliptic and Maximally Flat approaches were designed and analyzed. AWR Sonnet is used for the simulation and analysis of this filters.
\end{abstract}

Key words: Low Pass Filter Design, Microstrip Filter, Chebyshev Filter

\section{Introduction}

Microstrip low pass filter designs generally consist of two main steps. The first of these is the identification of a suitable low pass filter prototype. The selection of the frequency response, the ripple in the transmission band, and the number of reactive elements depend on the filter parameters required. The low pass filter is converted to LC elements to provide the element values of the first sample to provide the desired cutoff frequency and source impedance (typically $50 \mathrm{ohm}$ for microstrip applications). The second important step is to apply the appropriate microstrip realization with the obtained LC element circuit [1-3].

By means of sinusoidal voltage and current, the filters are energized and the output response is obtained. To understand the filter characteristics, there are different methods of interpreting the frequency responses taken at the output. These methods are; Transfer Function - $\mathrm{H}(\omega)$ (traditional approach), Attenuation - A( $\omega)$, S Parameters, ex. $\mathrm{S}_{21}(\omega)$, Others, ABCD Parameters and so on [4].

Low pass filters play an important role in RF/microwave communication systems. Transmitted and received signals have to be filtered at a certain frequency with a specific bandwidth. In this study, the design of low pass filter which are Chebyshev, Elliptic and Maximally Flat are done in

*Corresponding author: Address: Aselsan A.Ş., Mehmet Akif Ersoy Mahallesi, 296. Cadde, No: 16, 06370 Yenimahalle-Ankara, TURKEY. E-mail address: rtuzun@aselsan.com.tr, 
$\mathrm{RF} /$ microwave communication systems whose cutoff frequency is $6 \mathrm{GHz}$. After getting the specifications required, we designed and simulated the filters structure with the help of AWR Sonnet software.

In this paper, a novel the filter having best cutoff, highest attenuation and optimum design for production is presented. This filter having $6 \mathrm{GHz}$ cutoff frequency and having $42 \mathrm{~dB}$ at $6,6 \mathrm{GHz}$. The insertion loss is $-3,66 \mathrm{~dB}$ at $6 \mathrm{GHz}$.

\section{Chebyshev Filter}

Chebyshev filters are analog or digital filters having a steeper roll-off and more passband ripple (type I) or stopband ripple (type II) than Butterworth filters. Chebyshev filters have the property that they minimize the error between the idealized and the actual filter characteristic over the range of the filter, but with ripples in the passband [2]. The Chebyshev response is a mathematical strategy for achieving a faster roll-off by allowing ripple in the frequency response, but Chebyshev filters have a poor phase response.

The Chebyshev filter having passband ripple $L_{A r} \mathrm{~dB}$ and Cut Off frequency $\Omega_{c}=1$, is defined with functions below [1].

$$
\begin{aligned}
& \left|s_{21}(j \Omega)\right|^{2}=\frac{1}{1+\mathcal{E}^{2} T_{N}{ }^{2}(\Omega)} \\
& \mathcal{E}=\sqrt{10^{\frac{L_{A}}{10}}-1} \\
& T_{N}(\Omega)= \begin{cases}\operatorname{Cos}\left(n \cos ^{-1} \Omega\right) & \Omega \leq 1 \\
\operatorname{Cosh}\left(n \cosh ^{-1} \Omega\right) & \Omega>1\end{cases}
\end{aligned}
$$

Two-port circuit elements are defined as;

$$
\begin{aligned}
& g_{0}=1.0 \\
& g_{1}=\frac{2}{y} \sin \left(\frac{2}{2 n}\right) \\
& g_{i}=\frac{1}{g_{i}-1} \frac{4 \sin \left[\frac{(2 i-1) \pi}{2 n}\right] \cdot \sin \left[\frac{(2 i-3) \pi}{2 n}\right]}{y^{2}+\sin ^{2}\left[\frac{(i-1) \pi}{n}\right]} \quad \text { for } i=2,3, \ldots n \\
& g_{n+1}= \begin{cases}1.0 & \text { for odd number } n \\
\operatorname{coth}^{2}\left(\frac{\beta}{4}\right) & \text { for even number } n\end{cases} \\
& \beta=\ln \left[\operatorname{coth}\left(\frac{L_{A r}}{17.37}\right)\right] \\
& y=\sinh \left(\frac{\beta}{2 n}\right)
\end{aligned}
$$


Where $n$ is filter order, the values $g_{0}$ and $g_{n}$ represent the element values. For example, in a $5^{\text {th }}$ order filter design, the $\mathrm{N}$ value is 5 and the element value is 5 , so , $g_{0}$ to $g_{5}$ can be calculated $[5,6]$.

It is shown that in Table 1, the element values for different $L_{A r}$ values in different values of $n$. The filter order $n$ for the designed filter with the required passband ripple $L_{A r}$, minimum stop band suppression ratio $L_{A s} \mathrm{~dB}$ and minimum suppression rate frequency $\Omega_{\mathrm{s}}$ is defined as,

$n \geq \frac{\cosh ^{-1} \sqrt{\frac{10^{0,1 L_{A s-1}}}{10^{0,1} A r-1}}}{\cosh ^{-1} \Omega_{s}}$

For example ; $L_{A s} \geq 40 \mathrm{~dB}, \Omega_{s}=2$ and $L_{A r}=0,1 \mathrm{~dB}$, When these values are formulated, Chebyshev $n$ becomes ; $n \geq 5,45$, so filter order is chosen as 6 [1].

Table 1. The Chebyshev low pass filter element values ( $g_{0}=1.0$ (source impedance, $\Omega \mathrm{c}=1$ (cut-off frequency)) [1]

\begin{tabular}{|c|c|c|c|c|c|c|c|c|c|c|}
\hline \multicolumn{11}{|c|}{ For passband nipple $L_{d r}=0.01 \mathrm{~dB}$} \\
\hline$n$ & $g_{1}$ & $g_{2}$ & $g_{3}$ & $g_{4}$ & $g_{s}$ & $g_{6}$ & $g_{7}$ & $g_{\mathrm{a}}$ & $g_{3}$ & $g_{10}$ \\
\hline 1 & 0.0960 & 1.0 & & & & & & & & \\
\hline 2 & 0.4489 & 0.4078 & 1.1008 & & & & & & & \\
\hline 3 & 0.6292 & 0.9703 & 0.6292 & 1.0 & & & & & & \\
\hline 4 & 0.7129 & 1.2004 & 1.3213 & 0.6476 & 1.1008 & & & & & \\
\hline 5 & 0.7563 & 1.3049 & 1.5773 & 1.3049 & 0.7563 & 1.0 & & & & \\
\hline 6 & 0.7814 & 1.3600 & 1.6897 & 1.5350 & 1.4970 & 0.7098 & 1.1008 & & & \\
\hline 7 & 0.7970 & 1.3924 & 1.7481 & 1.6331 & 1.7481 & 1.3924 & 0.7970 & 1.0 & & \\
\hline 8 & 0.8073 & 1.4131 & 1.7825 & 1.6833 & 1.8529 & 1.6193 & 1.5555 & 0.7334 & 1.1008 & \\
\hline 9 & 0.8145 & 1.4271 & 1.8044 & 1.7125 & 1.9058 & 1.7125 & 1.8044 & 1.4271 & 0.8145 & 1.0 \\
\hline \multicolumn{11}{|c|}{ For passband ripple $L_{A r}=0.04321 \mathrm{~dB}$} \\
\hline$n$ & $g_{1}$ & $g_{2}$ & $g_{3}$ & $z_{4}$ & $g_{s}$ & $g_{6}$ & $g 7$ & $g_{a}$ & $g$ & $g_{10}$ \\
\hline 1 & 0.2000 & 1.0 & & & & & & & & \\
\hline 2 & 0.6648 & 0.5445 & 1.2210 & & & & & & & \\
\hline 3 & 0.8516 & 1.1032 & 0.8516 & 1.0 & & & & & & \\
\hline 4 & 0.9314 & 1.2920 & 1.5775 & 0.7628 & 1.2210 & & & & & \\
\hline 5 & 0.9714 & 1.3721 & 1.8014 & 1.3721 & 0.9714 & 1.0 & & & & \\
\hline 6 & 0.9940 & 1.4131 & 1.8933 & 1.5506 & 1.7253 & 0.8141 & 1.2210 & & & \\
\hline 7 & 1.0080 & 1.4368 & 1.9398 & 1.6220 & 1.9398 & 1.4368 & 1.0080 & 1.0 & & \\
\hline 8 & 1.0171 & 1.4518 & 1.9667 & 1.6574 & 2.0237 & 1.6107 & 1.7726 & 0.8330 & 1.2210 & \\
\hline 9 & 1.0235 & 1.4619 & 1.9837 & 1.6778 & 2.0649 & 1.6778 & 1.9837 & 1.4619 & 1.0235 & 1.0 \\
\hline \multicolumn{11}{|c|}{ For passband ripple $L_{\text {ar }}=0.1 \mathrm{~dB}$} \\
\hline$n$ & $g_{1}$ & $g_{2}$ & $g_{3}$ & $g_{4}$ & $g_{s}$ & $g_{6}$ & $g_{7}$ & $g_{x}$ & $g$ & $g_{10}$ \\
\hline 1 & 0.3052 & 1.0 & & & & & & & & \\
\hline 2 & 0.8431 & 0.6220 & 1.3554 & & & & & & & \\
\hline 3 & 1.0316 & 1.1474 & 1.0316 & 1.0 & & & & & & \\
\hline 4 & 1.1088 & 1.3062 & 1.7704 & 0.8181 & 1.3554 & & & & & \\
\hline 5 & 1.1468 & 1.3712 & 1.9750 & 1.3712 & 1.1468 & 1.0 & & & & \\
\hline 6 & 1.1681 & 1.4040 & 2.0562 & 1.5171 & 1.9029 & 0.8618 & 1.3554 & & & \\
\hline 7 & 1.1812 & 1.4228 & 2.0967 & 1.5734 & 2.0967 & 1.4228 & 1.1812 & 1.0 & & \\
\hline 8 & 1.1898 & 1.4346 & 2.1199 & 1.6010 & 2.1700 & 1.5641 & 1.9445 & 0.8778 & 1.3554 & \\
\hline 9 & 1.1957 & 1.4426 & 2.1346 & 1.6167 & 2.2054 & 1.6167 & 2.1346 & 1.4426 & 1.1957 & 1.0 \\
\hline
\end{tabular}




\section{Passive Low Pass Microstrip LC Filter Design}

The AWR Sonnet program was used for microstrip low pass filter design. All the filters were designed with lumped LC elements. Filters response can be obtained by simulating the filters. The dielectric constant of the substrate to be used in the filter to be designed is chosen as $\varepsilon_{r}=9.8$ and the thickness $d=10$ mils. Since the most suitable material to be used in production with thin film technology is alumina, alumina is preferred as sub-layer. In addition, there are 5 mil and 20 mil alumina options, although they are not very common in this technology. The alumina thickness determines the upper frequency limit. As the layer becomes thinner, designs can be made at upper limit frequencies. The 10 mil thickness used in these designs is sufficient for the desired frequency operating range. In addition, the use of 5 mil alumina is very thin due to the thickness of the production process is different and this application is much more difficult than using 10 mil. The main filter type was selected as the Distributed Stubs Filter, and the standard type was selected as the option [7-9].
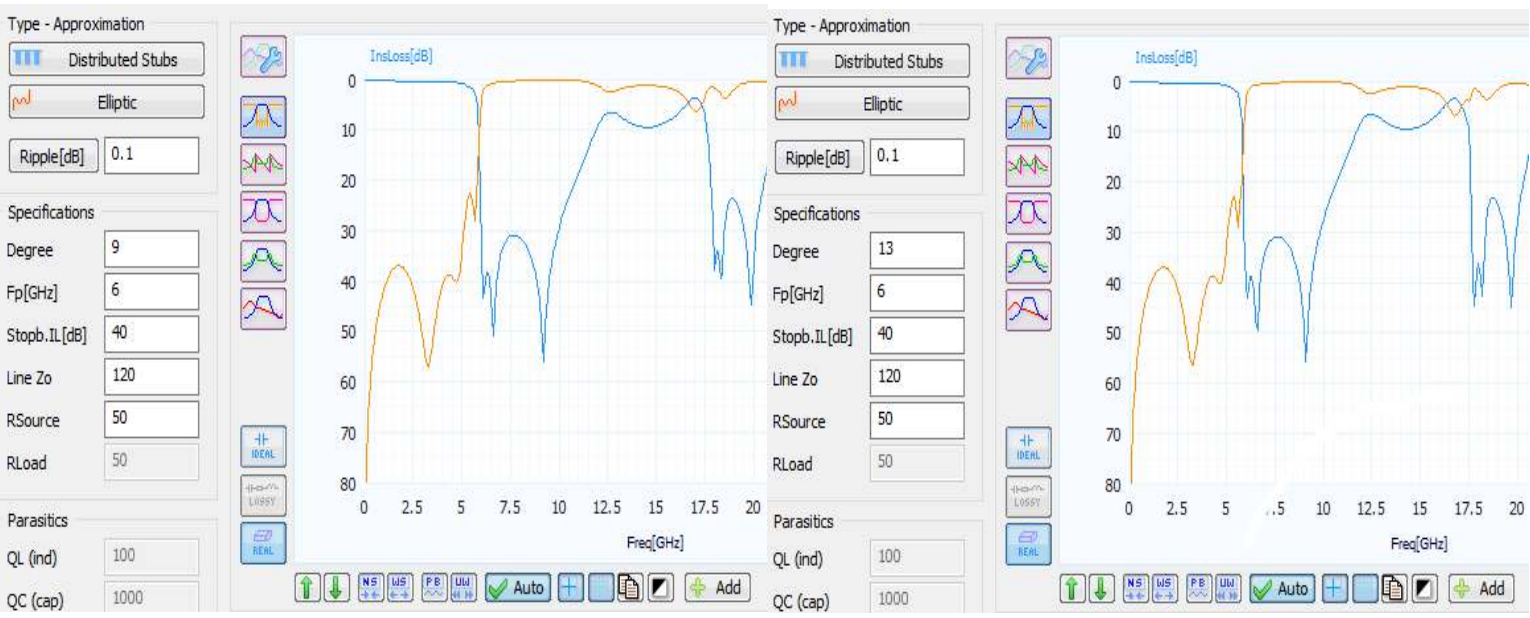

Figure 1. Designs for elliptic filter $9^{\text {th }}$ and $13^{\text {th }}$ orders respectively

After the determination of the filter type, an important step is to decide on which approach to make the desired filtration. After applying the elliptic filter selection from the common filter characteristics, the desired parameter values and different " $n$ " grades are entered as in the interface shown in Figure 1. The attempt to determine the smoothest filter response has been tried. It has been observed that increasing the number of " $n$ " in the elliptic filter structure does not have a significant effect on the filter frequency response. The filter design to be selected $15^{\text {th }}$ order that is closest to the required parameter values is shown in Figure 2. According to Figure 2, the filter quickly cut off from the transmission band to the stop band. However, it does not fully meet the need for large stop band. It appears that lower suppression ratios are obtained after $10 \mathrm{GHz}$ frequency.

By choosing Maximally Flat from the filter approaches, different " $n$ " grades shown in Figure 3 were selected and their effect was observed. As the filter grade increased, the cut-off curve of the filter at $6 \mathrm{GHz}$ improved. It has been determined that the $15^{\text {th }}$ order is the best result for filter needs (Figure 4). 


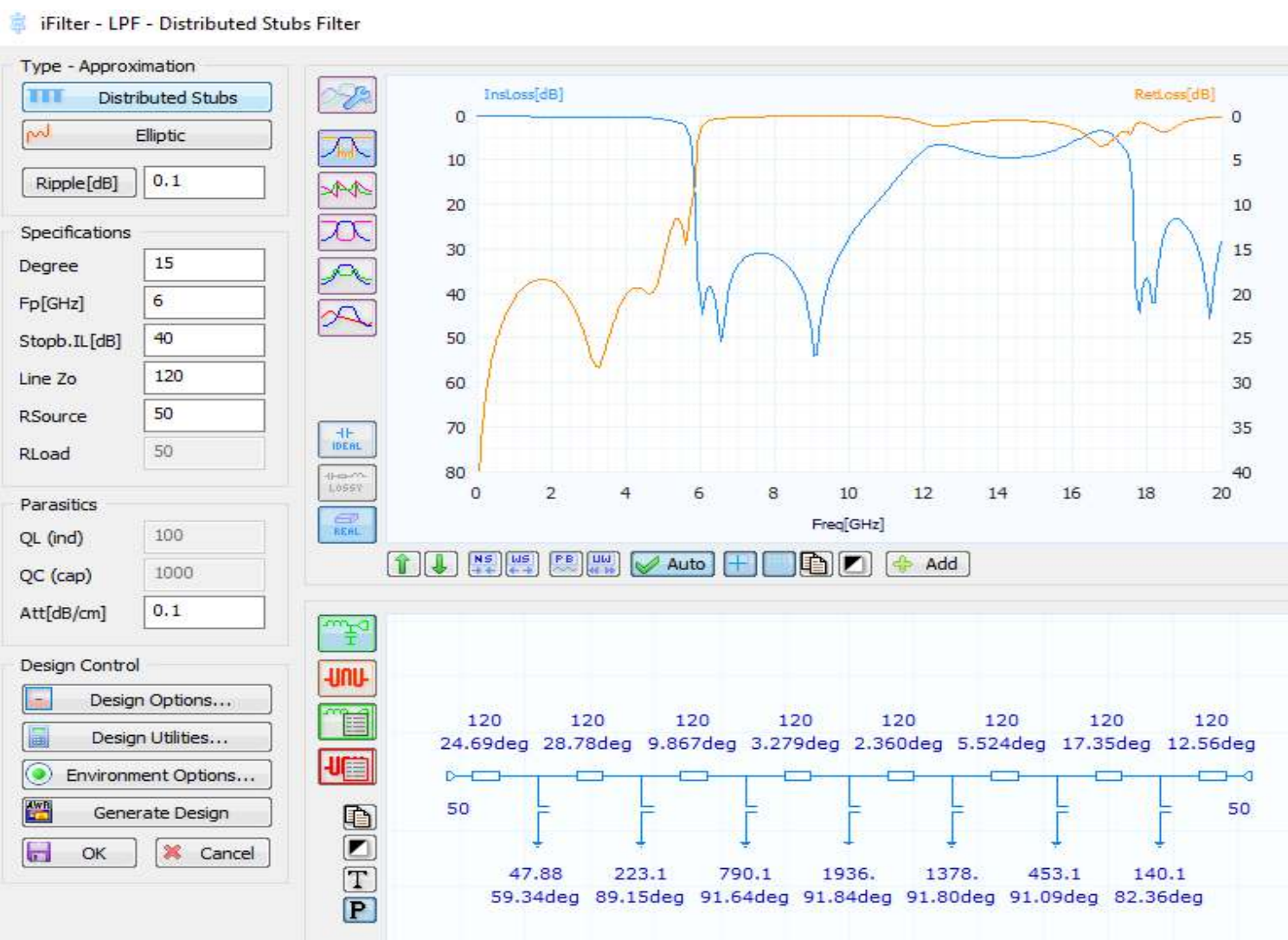

Figure 2. Simulation results and schematic representation of designed $15^{\text {th }}$ order for Elliptic filter
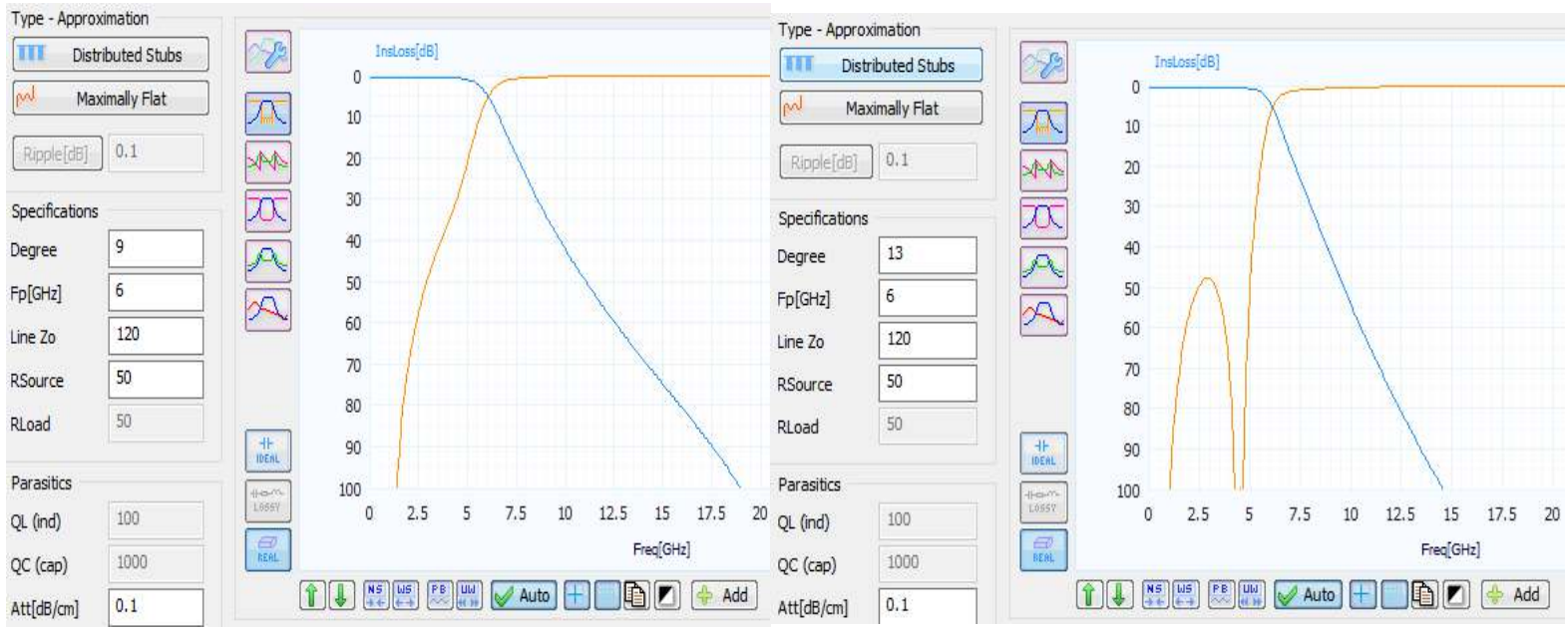

Figure 3. Filter designs for the Maximally Flat filter $9^{\text {th }}$ and $13^{\text {th }}$ respectively 


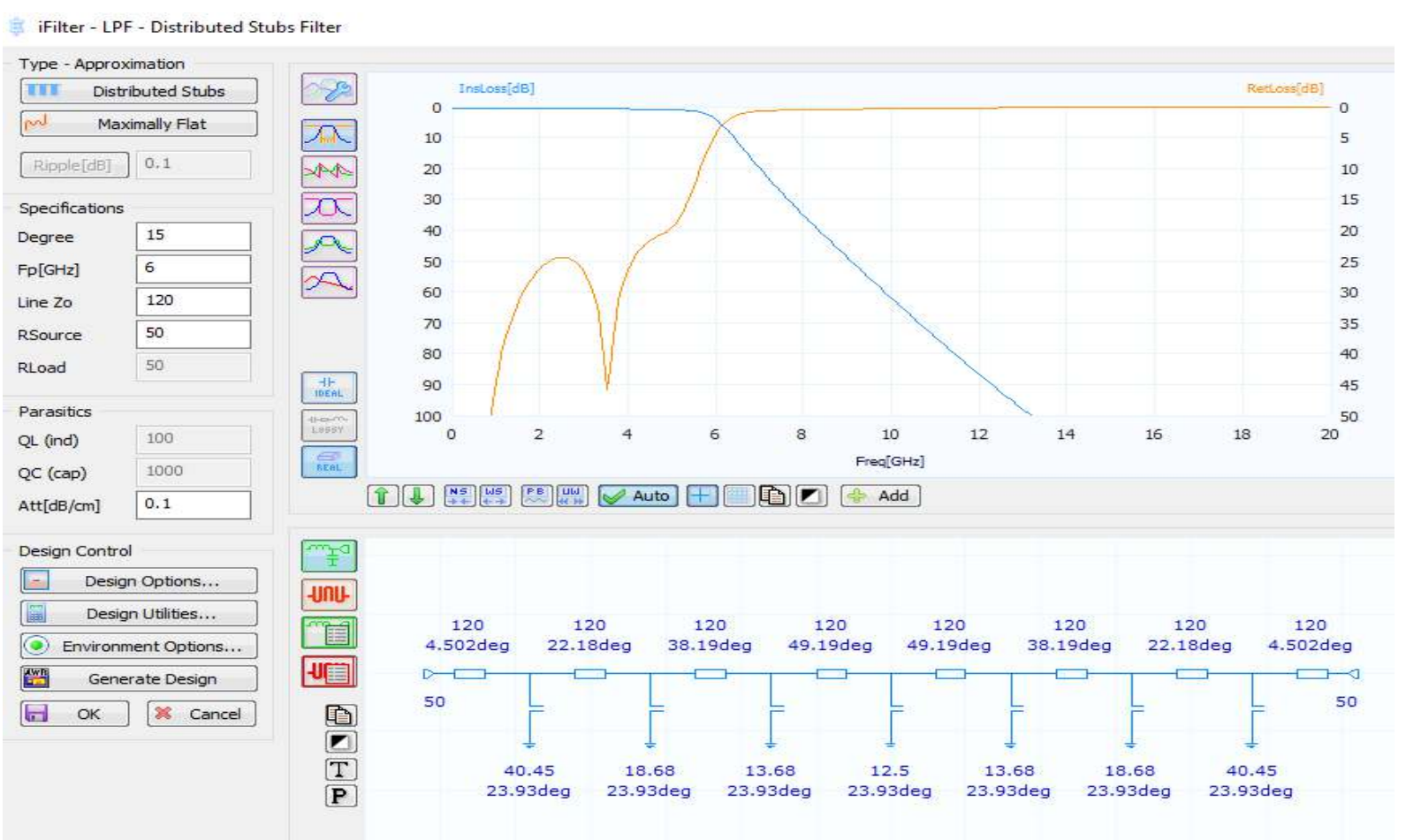

Figure 4. Simulation results and schematic representation of designed $15^{\text {th }}$ order for Maximally Flat filter

The Chebyshev selection, which is another common approach to microwave filters, was used to implement designs with different " $n$ " ratings in Figure 5. It has been observed that high compression ratio and fast cutting by increasing the number of filters.
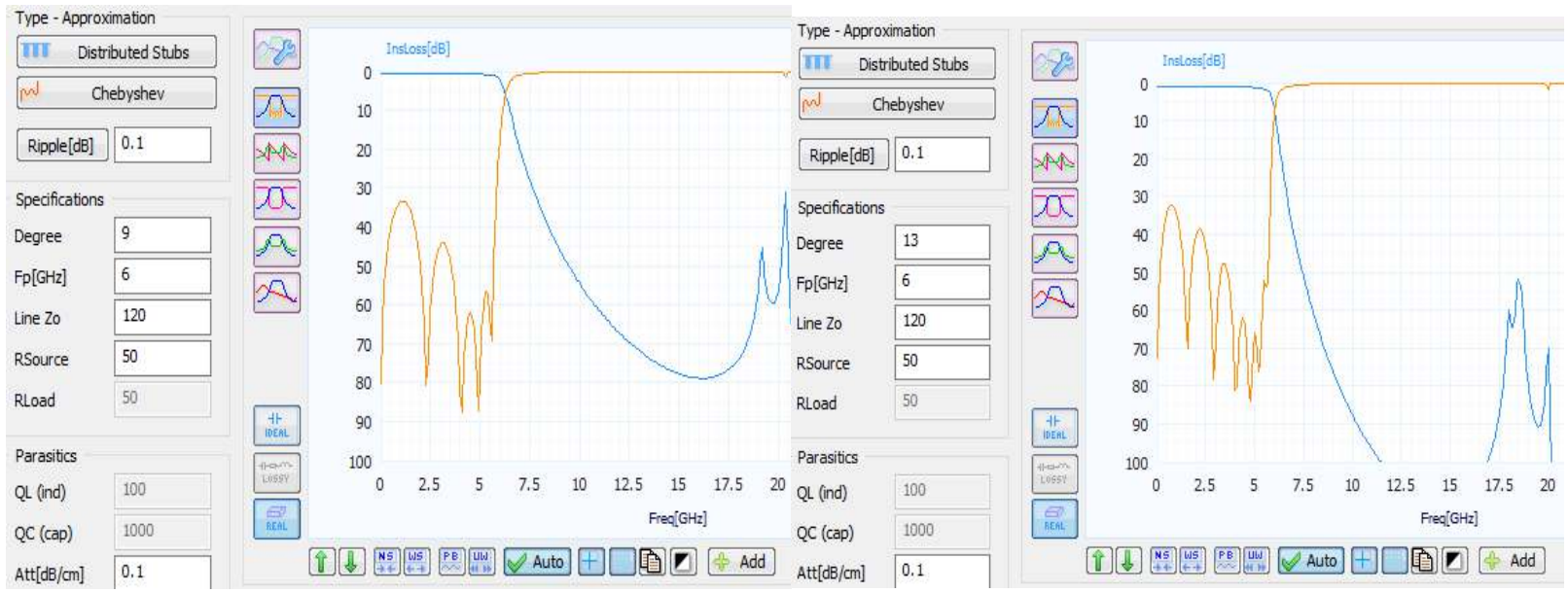

Figure 5. Filter designs for Chebyshev filter $9^{\text {th }}$ and $13^{\text {th }}$ order respectively

The best result for this approach was obtained at $19^{\text {th }}$ order (Figure 6). The result obtained with Chebyshev has satisfied the filter needs. 


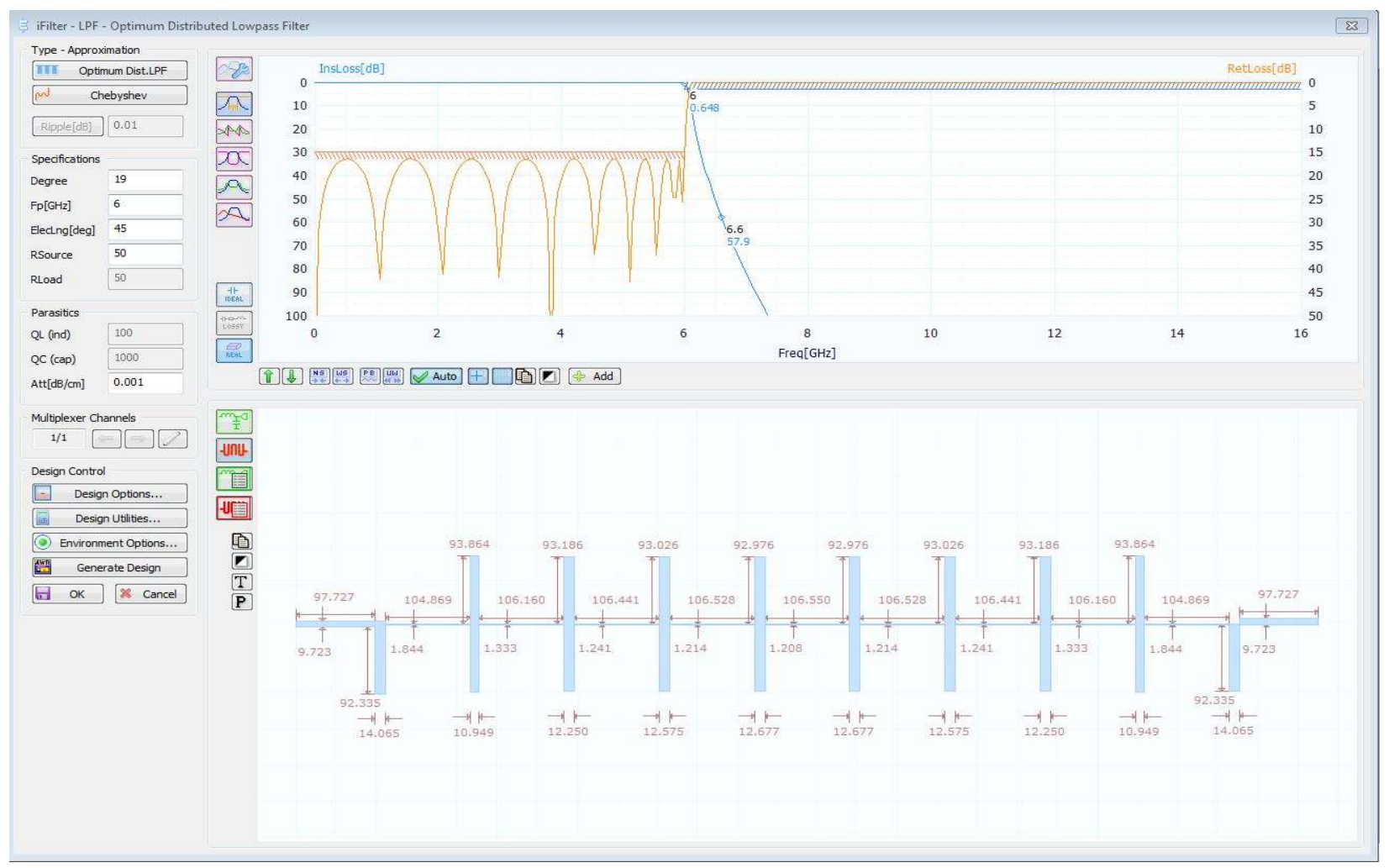

Figure 6. Simulation results and schematic representation of designed $19^{\text {th }}$ order for Chebyshev filter
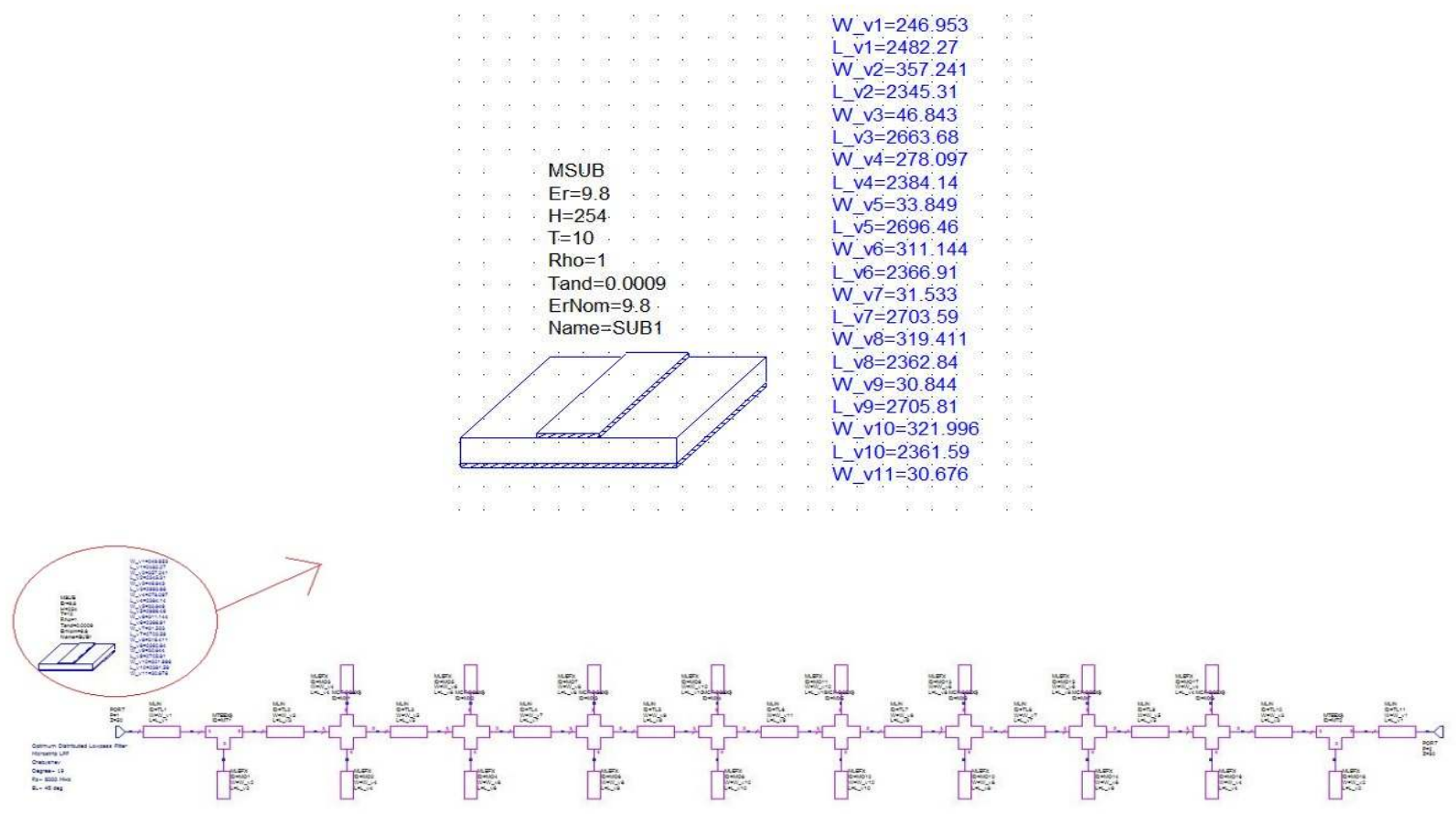

Figure 7. Physical circuit diagram of filter structure 
The measurement details of the filter structure shown in Figure 7. where $\mathrm{L}$ is the length and $\mathrm{W}$ is the width of structure. The two-dimensional (2D) visual structure of the designed filter is shown in Figure 8. This pattern can be placed on the substrate to produce the filter.

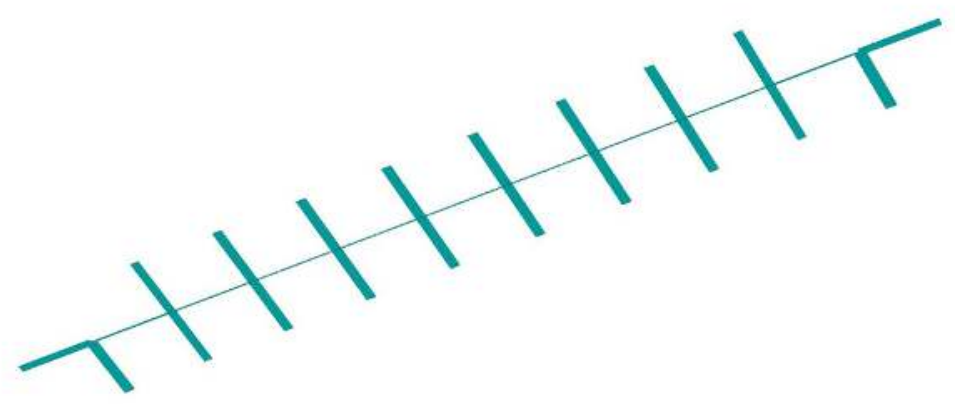

Figure 8. The 2D image of the designed filter (conductive part)

\section{AWR Filter Simulation Results}

The $\mathrm{S}_{21}$ (insertion loss) and $\mathrm{S}_{11}$ (return loss) parameters were simulated by using the Axiem Tool, which is an auxiliary tool of the AWR program of the microstrip low pass Chebyshev filter designed in the previous section. In this simulation, it is seen that the initial attenuation obtained as $57.9 \mathrm{~dB}$ at $6.6 \mathrm{GHz}$ is $46.34 \mathrm{~dB}$, as shown in Figure 9. Another important point is losses. Loss is $0.648 \mathrm{~dB}$ in design and $3.66 \mathrm{~dB}$ in simulation at $6 \mathrm{GHz}$. This values are within acceptable limits.

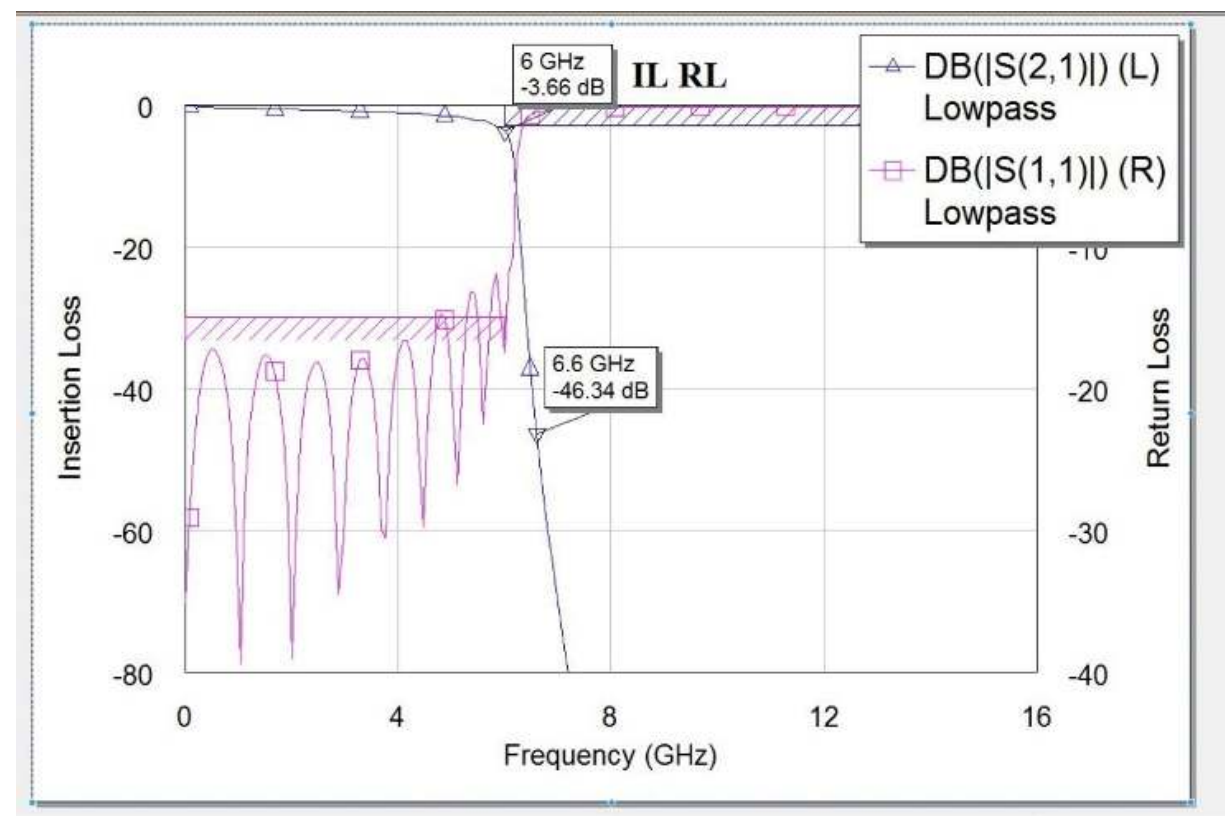

Figure 9. Simulation result obtained with AWR Axiem Tool 


\section{Conclusions}

This paper describes the design of low cost and low insertion loss microstrip LC low pass filter by using microstrip layout which works at $6 \mathrm{GHz}$ for relative permittivity $\varepsilon_{r}=9.8$ value with a substrate thickness 10 mils. The design and simulation are performed using AWR Sonnet software. All filters are required in all RF-communication techniques. In this paper, we checked the filters performance using S parameters. Different designs have been developed using Maximally Flat, Chebyshev and Elliptic approaches as the most common approaches used in filter design. The parameters such as cutting curves, attenuation, and production suitability of these designs have been evaluated and simulated by implementing a Chebyshev polynomial design that is most appropriate for production and other requirements. In this study, since the desired suppression rate is high, the $19^{\text {th }}$ degree, which is the last filter level of the program, was selected. It was obtained the highest suppression attenuation value was $57.9 \mathrm{~dB}$.

\section{References}

[1] Hong J. and Lanchester M. J., Microstrip Filters for RF/Microwave Applications, Singapur, John Wiley \& Sons Inc.: 2001.

[2] Rajasekaran K., Jayalakshmi J., and Jayasankar T., Design and Analysis of Stepped Impedance Microstrip Low Pass Filter Using ADS Simulation Tool for Wireless Applications, International Journal of Scientific and Research Publications, 2013.

[3] Solanki A., Sharma N., and Kumar Gupta H., Design of Microstrip Low Pass Filter for LBand Application, International Journal of Electronics and Electrical Engineering, 2015: 3(3), 212-215.

[4] İnternet: Fabian Kung Wai Lee. (2007). RF/Microwave Filters. URL: http://www.webcitation.org/query?url=http $\% 3 \mathrm{~A} \% 2 \mathrm{~F} \% 2 \mathrm{Fpesona.mmu.edu.my \% 2F \% 7Ewlk}$ ung\%2FADS\%2Frf\%2Flesson3b.pdf\&date=2018-07-13, Son Erişim Tarihi : 13.07.2018

[5] Chauhan D. and Raval F., Design of Microstrip Low Pass Filter, International Journal of Innovative and Emerging Research in Engineering, 2016: 3(4).

[6] Kumar P. and Chaturvedi A., Design and Analysis of Microstrip Elliptical Low Pass Filter, International Conference on Emerging Trends in Electronic and Photonic Devices and Systems, 2009.

[7] Selçuk O, and Kızılbey O., Design and Realization of Different Microstrip Low Pass Filter Topologies by aid of AWR Microwave Office iFilter Wizard, 9th International Conference on Electrical and Electronics Engineering, 2015.

[8] Gadhvi D., Patel S., and Kosta Y., Elliptic Low Pass Filter Design using DGS Slot for Microstrip Lines, Nirma University International Conference on Engineering (NUICONE), 2013.

[9] Boudaa S., Challal M., Mehani R., and Rabahallah D., Miniaturized Ultra-Wide Stopband Microstrip Low Pass Filter Design, 4th International Conference on Electrical Engineering (ICEE), 2015. 